\title{
Mental health in Zimbabwe
}

\section{Walter Mangezi MMed Psychiatry ${ }^{1}$ and Dixon Chibanda MMed Psychiatry MPH ${ }^{2}$}

\author{
'Lecturer, Department of Psychiatry, Faculty of Health Sciences, University of Zimbabwe, email wmangezi@yahoo.co.uk
} ${ }^{2}$ Consultant Psychiatrist, Harare Hospital, Zimbabwe

\begin{abstract}
7 imbabwe is a landlocked country which has recently emerged from some marked political and socioeconomic challenges. Against this background, mental health has fallen down the priority list, as matters such as food shortages and the AIDS scourge have taken precedence. Zimbabwe is in southern Africa; Zambia and Botswana lie to the north, Namibia to the west, South Africa to the south and Mozambique to the east. Its population is 11.4 million. The capital city is Harare, which has a population of 1.6 million.
\end{abstract}

\section{Recent health service history}

Zimbabwe had centralised health services prior to 1980. In 1984 a project was set up to decentralise health services by upgrading the infrastructure. Each of the country's nine provinces had a provincial hospital built or refurbished. The provinces are subdivided into districts, and district hospitals were also built or refurbished. In each district there are smaller hospitals, called health centres. In the community, local clinics were built within a radius of $10 \mathrm{~km}$ of all households. A referral system was put in place where patients accessed treatment at clinics and were referred via the different levels of services up to the central hospitals. Unfortunately, there was pressure to reduce public spending and the projects had to be abandoned before completion. Each of the provincial hospitals was supposed to have a psychiatric unit and the district hospitals psychiatric beds. The project was abandoned before this could be achieved. The problem was made worse with the political and socioeconomic crisis which began in 2000. Psychiatric nurses began to emigrate in large numbers and health services gradually became centralised again. Mental health services were once free for all but this became unsustainable as the country's economy contracted. Social workers were then used to determine who had the means to pay hospital fees and who would be given permission to access free mental health services. The country's economy is now showing signs of stability and the process of decentralisation is being re-implemented. Mental health services are free again in all government facilities.

\section{Mental health services}

There are six public institutions with psychiatric beds: Harare Hospital Psychiatric Unit, Parirenyatwa Hospital Annexe, Ingutsheni Hospital, Mpilo Hospital Psychiatric Unit,
Ngomahuru Hospital and Mutare Hospital Sakubva Unit. In addition, three facilities provide forensic psychiatry services: Mlondolozi Special Institution, Harare Central Prison and Chikurubi Special Institution. The facilities available are not suitable for children or the elderly. Parirenyatwa Hospital Annexe and Harare Hospital Psychiatric Unit are the only institutions with a psychiatrist.

The staff of Zimbabwe's mental health services comprise: a deputy director, a mental health manager and nine provincial mental health coordinators, plus seven psychiatrists - one working for the government, two for the medical school and the others in private practice. They all work in Harare. The country welcomes any foreign English-speaking psychiatrists on condition they are registered and licensed with the Zimbabwe Medical and Dental Council. The only challenge is the low remuneration. Foreign psychiatrists can assist the university by identifying a project sponsored by a donor or research project.

The country has one child psychiatrist, who is in the private sector. All the psychiatrists belong to the Zimbabwe College of Psychiatrists, which discusses issues related to mental health in the country and administers continuing medical education (CME) for psychiatrists and other medical practitioners. The College has no formal links with other psychiatric associations in the region or further abroad, but works with the Zimbabwe Therapist Association, whose membership comprises psychologists and counsellors.

The primary healthcare clinics serve psychiatric patients. They screen psychiatric patients, refer them to the psychiatric hospitals and are involved in follow-up (mainly resupply of medication).

In addition, some non-governmental organisations (NGOs) offer mental health services. The main one is the Zimbabwe National Association for Mental Health (ZIMNAMH), which represents the interests of people with mental illness. It was founded in 1981 and has been the main vehicle for advocacy for mental health services. The Association has been involved in rehabilitation; its main project is based at Tirivanhu Farm. Amani Trust is an organisation which helps torture victims and promotes human rights. There are also organisations that look at the psychosocial issues of HIV/AIDS.

In the informal sector, the Zimbabwe National Traditional Healers Association (ZINATHA) has a big role in the management of psychosomatic and anxiety disorders. ZINATHA has attempted to educate its members in the referral of patients with mental health problems to the formal sector. Unfortunately, there has not been much collaboration between the formal and informal sectors. Psychiatrists could do more in the training of traditional healers. 


\section{Training}

There is one medical school, at the University of Zimbabwe. The Department of Psychiatry teaches undergraduate medical students and offers a 1-year tertiary diploma in mental health and a 3-year masters degree in psychiatry. Normally, the diploma has four students and the masters degree has up to two candidates in each year (currently there is one student in the first year, none in the second year and two in the third year). Psychiatry is the least popular of the medical specialties because the remunerations in private practice are the lowest. Psychiatric nurses are trained at Ingutsheni Hospital. The programme is 18 months and normally has approximately 12 students.

\section{Mental health disorders}

In Zimbabwe in-patients typically present with schizophrenia, substance-induced psychosis, bipolar affective disorder (mania), epilepsy or the psychiatric complications of HIV. In the psychiatric out-patient clinics and private practice, depression, substance dependency and anxiety disorders are also typical. Eating disorders and personality disorders are diagnoses rarely made among the Black population. The reason for this might be a poor detection rate by health personnel. Research on the prevalence of personality disorder would be an area of interest.

\section{Mental health policy}

Zimbabwe's mental health policy was introduced in 1999 and has attempted to decentralise services. Coordinators have now been established in each province. The economic downturn has slowed the establishment of community mental health centres. An important emphasis of the policy is to incorporate mental health within the national HIV/AIDS programme.

\section{Mental health legislation}

The Mental Health Act of 1976 was repealed in 1996. The country now uses the Mental Health Act 1996 No. 15, which safeguards the rights of a patient but still emphasises institutionalisation of those who are mentally ill. An extensive mental health training programme focusing on the rights of offenders with mental disorders was provided for officers of the courts between 2006 and 2008. This led to a substantial decline in the incarceration of people who are mentally ill when brought before the courts for minor offences.

\section{Publications and research}

The country does not have a psychiatric journal. Most research work is being done into the psychosocial aspects of HIV and depression. Earlier research has, however, led to the development of indigenous screening tools for common mental disorders. There is currently a move to incorporate use of the validated Edinburgh Postnatal Depression Scale into the routine 6-week postnatal visit at primary postnatal clinics. At primary city health clinics, lay health workers since 2006 have screened for common mental disorders using the Shona Symptom Questionnaire (SSQ-14), an indigenous screening tool. The lay health workers then provide structured problem-solving therapy. There is a need to carry out a randomised controlled trial of this intervention delivered by lay health workers.

\section{Conclusion}

In Zimbabwe, mental health services have come a long way. The harsh socioeconomic environment slowed the process of decentralisation which was embarked on when the Mental Health Act and policies were reviewed. The central structures are now in place and services are being brought to the people. As socioeconomic conditions improve, the country can increasingly focus on the setting up of community mental health services; it also needs to encourage more medical and nursing students to train in mental health and to arouse greater interest in mental health research.

\section{Sources}

World Health Organization (2009) See http://www.afro.who.int/en/ zimbabwe/who-country-office-zimbabwe.html (accessed July 2010).

Zimbabwe Ministry of Health and Child Welfare (2009) See http://www. mohcw.gov.zw (accessed July 2010).

\section{Help for Pakistani flood victims}

More than 20 million people have been affected by the floods in Pakistan, in particular in the Khyber Pukhtoonkhwa Province (formerly known as North West Frontier Province). More than 3.5 million children are in immediate physical and mental health danger. More than 5 million people require emergency relief. Urgent rescue and healthcare needs are the top priorities.

The Horizon agency, chaired by a College Fellow, has stepped in to help with relief efforts. An emergency medical relief centre has been established at Ibadat Hospital in Peshawar City, with a two-pronged service-delivery mechanism:

- attending to patients who require mild to moderate medical cover, such as for skin infections, chest infections, mild cuts and abrasions - sending people who are acutely and severely physically ill (and pregnant women) to secondary or tertiary hospitals.

Those presenting with mental health problems to the Ibadat Hospital emergency centre will be referred by a qualified and experienced team of psychiatrists and psychologists under my own supervision. These professionals are highly skilled in disaster and first-aid mental health management. In addition, the immediate social needs of the victims will be met as far as possible. 